\title{
DE LA COMPRAVENTA
}

\section{Jorge Fernández Stevenson}

Trata este comentario jurisprudencial del tema correspondiente a los efectos del pacto comisorio calificado en contratos diversos de la compraventa, y la discusión doctrinaria y jurisprudencial que lo acompaña.

Sobre el particular, recordemos que el pacto comisorio está contenido en el Párrafo X, Título XXIII del Libro IV del Código Civil, a propósito del incumplimiento de la obligación de pago del precio en el contrato de compraventa, y cuyo concepto lo entrega el artículo 1877 que expresa, en su inciso primero: "Por el pacto comisorio se estipula expresamente que, no pagándose el precio al tiempo convenido, se resolverá el contrato de venta”.

La doctrina clasifica el pacto comisorio en simple y calificado.

El pacto comisorio simple no es más que la condición resolutoria tácita expresada en el contrato. Por ejemplo, en un contrato de arrendamiento se conviene que si el arrendatario no paga la renta en la oportunidad prefijada, éste se extinguirá o, si en un contrato de compraventa, se establece que si el comprador no paga el precio, se resolverá el contrato.

Por su parte, el pacto comisorio calificado, o con cláusula de ipso facto, se define como el acuerdo de las partes en orden a dejar sin efecto el contrato, de inmediato, ipso facto, si el deudor incumple sus obligaciones. Existe acuerdo a este respecto en que no es necesario emplear fórmulas sacramentales, y que existirá un convenio de este tipo cada vez que aparezca clara la intención de que se produzca la resolución o extinción inmediata del contrato por el sólo hecho del incumplimiento, sin necesidad de resolución judicial que así lo declare.

En lo relativo al pacto comisorio calificado en el contrato de compraventa, sus efectos están regulados en el artículo 1879 del Código Civil, que señala: "Si se estipula que por no pagarse el precio al tiempo convenido, se resuelva ipso facto el contrato de venta, el comprador podrá, sin embargo, hacerlo subsistir, pagando el precio, lo más tarde, en las veinticuatro horas subsiguientes a la notificación judicial de la demanda". Como se observa, aún en una estipulación de este tipo, no cesa el contrato por el mero incumplimiento, toda vez que todavía se le otorga al comprador la facultad de enervar la acción de resolución pagando el precio adeudado dentro del plazo de veinticuatro horas siguientes a la notificación de la demanda. Esto es, la resolución no opera de pleno derecho, sino que impone la necesidad de demandar, otorgando la posibilidad al deudor de persistir en el contrato pagando, y sólo si así no se hace, el tribunal procederá a declarar su resolución.

\footnotetext{
Profesor de Derecho Civil, Escuela de Derecho, Universidad Católica del Norte, sede Coquimbo.
} 
Ahora bien, en la actualidad ya no hay dudas que el pacto comisorio, aún encontrándose previsto a propósito del contrato de compraventa y específicamente por el incumplimiento de la obligación de pago del precio, puede establecerse también en cualquier otro contrato y por el incumplimiento de cualquier otra obligación.

El problema que surge en este punto es determinar qué normas se van aplicar en este caso, esto es, si las de la compraventa, en donde se trata este pacto, y con los efectos propios que allí se contemplan, o bien, las normas que puedan haberse dado las partes, situación que resulta de trascendencia esclarecer, toda vez que, si se estima lo primero, dicho pacto no operará de pleno derecho conforme ya se ha señalado y, en el segundo caso, deberá estarse a lo que hayan convenido las partes, es decir, que de no cumplirse lo pactado, se resuelva o extinga efectivamente "de inmediato" o ipso facto el contrato respectivo, de pleno derecho, sin que pueda el deudor enervar la acción pagando.

Al respecto, existen dos corrientes doctrinarias. La primera estima que si resulta lícito estipular el pacto comisorio con cláusula ipso facto en otros contratos diversos a la compraventa debería aplicárseles por analogía el artículo 1879 y, en consecuencia, el deudor puede enervar la resolución del contrato pagando dentro de las 24 horas siguientes a la notificación de la demanda, situación ésta que se traduce en que el contrato no se resuelve de pleno derecho, requiriéndose de una declaración judicial para ello.

La otra tesis, sostiene que en casos como el descrito el pacto comisorio opera de pleno derecho, porque es eso lo que las partes pretendieron al estipularlo y no se está en la situación del artículo 1879 del Código Civil que regula un caso particular, sino frente a un pacto creado por las partes en virtud del principio de la autonomía de la voluntad del artículo 1545 del referido código. En tal caso, y tratándose, por ejemplo, del contrato de arrendamiento, si se produce el incumplimiento, el arrendador deberá demandar solicitando simplemente la restitución del inmueble y no la terminación, porque el contrato ya se extinguió al producirse el incumplimiento.

Al respecto, puede señalarse que la jurisprudencia ha recogido ambas interpretaciones. Una sentencia de la Excma. Corte Suprema, en materia de arrendamiento, resolvió que la resolución opera por sentencia judicial y aplicó por analogía el artículo 1879 del Código Civil (RDJ, T. 38, sec. I, p. 318). En el mismo sentido RDJ, T. 86 , sec. $5^{\text {a }}$, p. 92 .

Por otra parte, en sentencia de la Excma. Corte Suprema publicada en la RDJ, T. 48 , sec. $1^{\text {a }}$, p. 109 , de fecha 2 de Julio de 1948 , se acoge la segunda tesis, señalando que en los contratos de arrendamiento las partes pueden estipular la terminación ipso facto del contrato por incumplimiento de las obligaciones de alguna parte y que esta estipulación surte los efectos que aquéllas quisieron

\footnotetext{
Citadas en René Ramos Pazos, "De las Obligaciones", Colección Manuales Jurídicos $N^{\circ} 110,1^{\circ}$ Edición, Editorial Jurídica de Chile, 1999.
} 
atribuirle, sin necesidad de acción en donde se pida la terminación ni sentencia que la declare,

Del análisis de la jurisprudencia más actual, se observa que la controversia no está dirimida y, así, en fallo de 28 de Julio de 1992 de la Corte de Apelaciones de Concepción, también en relación al contrato de arrendamiento, se estableció que aún cuando en dicho contrato se incorporó una cláusula que importó un pacto comisorio, ello no implica que para la puesta en mora del deudor, deben efectuarse las dos reconvenciones que prescribe la ley especial, y sólo entonces, en el caso que el arrendatario no pague dentro de los plazos designados, podrá el juez declarar la terminación del contrato y ordenar luego la restitución. Se agrega en este fallo que el artículo 1977 del Código Civil (en que se establece la exigencia de las dos reconvenciones legales) constituye una norma de orden público, y como tal, importa una excepción al principio de la autonomía de la voluntad y por tanto, el pacto que es su expresión no tiene el efecto de ipso iure de que se habla y el acreedor no ha podido dar por terminado el contrato, como aparece haciéndolo expresamente y pidiendo como consecuencia la restitución directa de la casa arrendada (GJ No 145, p. 80 ).

No obstante lo referido y otros similares casos, en las sentencias más recientes de los tribunales, es posible observar una mayor tendencia a estimar la aplicación del pacto comisorio en términos amplios, respetando la voluntad de los contratantes, que también constituye una ley particular de acuerdo al artículo 1545 del Código Civil. Así se resuelve en sentencia de 4 de Abril de 2001, de la Corte de Apelaciones de Santiago, a propósito del contrato de arrendamiento (GJ., Mayo 2001, N² 251, p. 86), señalándose en el fundamento $1^{\circ}$ que "las partes acordaron que la falta de pago de dos mensualidades sucesivas producirá i $p$ so facto la resolución del contrato, quedando facultado el arrendador para retirar los avisos inmediatamente y demandar a título de indemnización de perjuicios la renta íntegra de las mensualidades que faltan para completar el plazo de vigencia convenido, adquiriendo el arrendatario la calidad de depositario, debiendo restituirlo inmediatamente al arrendador"; $2^{\circ}$ "Que la cláusula transcrita en el razonamiento anterior importa un pacto comisorio calificado con cláusula de resolución ipso facto que las partes de este juicio convinieron libremente y que constituye una ley particular que deben respetar"; y $3^{\circ}$ "Que, en consecuencia, no cabe otra cosa a esta Corte sino constatar que los contratos de arrendamiento sub lite terminaron indefectiblemente el día 31 de octubre de 1990, lo que se produjo por el no pago de las rentas correspondientes a los meses de septiembre y octubre del señalado año".

Igualmente, el mismo criterio se puede observar en otras instituciones jurídicas, como se resuelve a propósito de la dación en pago con pacto comisorio calificado, en sentencia de fecha 26 de Julio de 2001, de la Excma. Corte Suprema (GJ., Junio 2001, No252, p. 66), que se comenta. 


\section{DACIÓN EN PAGO CON PACTO COMISORIO CALIFICADO. INCUMPLIMIENTO PRODUCE LA RESOLUCIÓN IPSO IURE.}

"Santiago, 26 de junio de 2001.

\section{Vistos:}

En estos autos Rol No 103.061 del Primer Juzgado Civil de Concepción, por sentencia de 15 de enero de 1999, el juez titular de dicho tribunal acogió la demanda deducida por la Cooperativa de Viviendas y Servicios Habitacionales Rafael Sotomayor Limitada en contra de Inversiones y Renta San Pablo S. A. y, en consecuencia, entendiendo resuelto el contrato de compraventa celebrado por las partes por escritura pública de 23 de julio de 1991, complementada por escritura de esta misma fecha y modificada por escritura pública de 13 de agosto de 1993, ordenó a la demandada la restitución a la actora del inmueble objeto de este contrato, con indemnización de perjuicios, reservando a la demandante el derecho a discutir acerca de la especie o monto de los perjuicios a indemnizar en la etapa de ejecución de la sentencia o en otro juicio diverso. La parte demandada impugnó esta resolución mediante la interposición de los recursos de casación en la forma y apelación. Una Sala de la Corte de Apelaciones de Concepción, el 4 de octubre de 1999, rechazó el primero y, conociendo del segundo, confirmó el fallo de primer grado sin modificaciones. Contra la sentencia de segunda instancia, la sociedad demandada dedujo recursos de casación en la forma y en el fondo.

Se trajeron los autos en relación.

Considerando:

En cuanto al recurso de casación en la forma.

Primero: Que la recurrente sostiene que la sentencia impugnada ha incurrido en la causal $4^{a}$ del artículo 768 del Código de Procedimiento Civil, esto es, la ultra petita, por cuanto "no guarda relación ni considera el objeto que se contiene en la demanda". En efecto, agrega, la actora ha señalado que su parte ha incumplido su obligación de pagar el precio del contrato de compraventa celebrado entre ambos y que, por ello, debe declararse la resolución del contrato y el fallo razona y resuelve una cuestión distinta, a saber, la restitución de un inmueble como consecuencia de una resolución que no declara y que sólo constata.

Segundo: Que el vicio de ultra petita se produce cuando la sentencia otorga más de lo pedido por las partes o se extiende a puntos no sometidos a la decisión del tribunal, es decir, cuando apartándose de los términos en que las partes situaron la controversia por medio de sus respectivas acciones o excepciones, altera el contenido de éstas cambiando su objeto o modificando su causa de pedir.

Tercero: Que en la especie, la demandante solicitó al tribunal la restitución de un inmueble por haber operado en el contrato de compraventa aludido en lo expositivo el pacto comisorio calificado, pidiendo expresamente que se declarara 
"que el contrato de compraventa que se individualiza en el cuerpo del escrito está resuelto" y que como consecuencia de lo anterior se "condene a la sociedad demandada a restituir el bien raíz...". La sentencia de primera instancia, confirmada sin modificaciones por la de segundo grado, hizo lugar a la demanda y declaró que "encontrándose resuelto el contrato de compraventa celebrado por las partes..., se condena a la demandada a restituir el inmueble objeto de ese contrato...".

Cuarto: Que como puede apreciarse, al resolver el litigio los jueces del fondo en la forma aludida, no han incurrido en el vicio denunciado desde que se acogió la demanda, que pretendía la restitución de una determinada cosa, precisamente por la causa de pedir alegada, a saber, el haber operado el pacto comisorio calificado que contenía el contrato de compraventa celebrado por las partes. La nulidad formal impetrada, entonces, será desestimada.

En cuanto al recurso de casación en el fondo.

Quinto: Que en concepto de la recurrente, la sentencia ha cometido errores de derecho que han influido sustancialmente en su parte dispositiva y que, por ende, debe ser invalidada. Tales errores serían los siguientes:

a) se ha infringido el artículo 1879 del Código Civil al declarar que el contrato de compraventa se ha resuelto ipso facto en virtud del pacto comisorio calificado, toda vez que la resolución, cuando se trata del incumplimiento de la obligación de pagar el precio en un contrato de compraventa, nunca opera de pleno derecho y siempre requiere de una resolución judicial que la declare;

b) se han vulnerado los artículos $1560,1562,1563$ inciso primero y 1564 inciso primero del Código Civil, pues la sentencia desechó la excepción de contrato no cumplido opuesta por su parte basándose en que la obligación de la demandante de alzar una hipoteca nacía sólo cuando se obtuviera la aprobación definitiva de la Dirección de Obras de la Municipalidad de Concepción, en circunstancias que, de acuerdo al texto del contrato, tal obligación nacía al obtenerse la "aprobación previa" por parte de la misma repartición municipal, la que se otorgó;

c) se ha conculcado el artículo 1552 del Código Civil al rechazarse por el fallo la excepción de cumplimento, pues su parte obtuvo la "aprobación previa" de la Dirección de Obras, que era lo que exigía el contrato de compraventa y si no pudo obtener la aprobación definitiva fue por fuerza mayor, debido a la imposibilidad de obtener agua potable para todo el sitio;

d) se ha infringido el mismo artículo 1552 del Código Civil al estimar la sentencia que no estaba renunciada la acción absolutoria, en circunstancias que ello se pactó expresamente en el contrato; y

e) se han vulnerado los artículos 1560 y 1564 inciso primero del Código Civil, en relación con la fuerza mayor, toda vez que es un hecho que desde la cota 58 hacia los niveles superiores del terreno no existía factibilidad para otorgar los servicios de agua potable y alcantarillado.

Sexto: Que son hechos establecidos en la sentencia que se revisa los siguientes: 
a) por escritura pública de 23 de junio de 1991, complementada por escritura de la misma fecha, la Cooperativa de Viviendas y Servicios Habitacionales Rafael Sotomayor Limitada vendió a Inversiones y Rentas San Pablo S. A. el predio ubicado en Avenida Inglesa $N^{\circ} 420$ de la comuna de Concepción, de una superficie aproximada de 240.570 metros cuadrados.

b) el precio de la compraventa se pactó en $\$ 359.135 .656$, precio que debía solucionarse mediante la dación en pago de 43 viviendas de determinadas características que la compradora debía edificar.

c) por escritura pública de 13 de agosto de 1993, se modificó el contrato anterior en el sentido que el precio debía pagarse mediante la dación en pago de 44 viviendas de determinadas características que la compradora debía construir en el mismo predio en el plazo de cinco años contado desde la fecha en que la Dirección de Obras Municipales de Concepción aprobara el proyecto de urbanización y loteo del predio, debiendo la compradora obtener en el plazo de 180 días contados desde el 28 de julio de 1993 la aprobación previa del loteo general y los proyectos de urbanización de primera etapa o Lote $\mathrm{D}$ del inmueble vendido;

d) se estipuló que si la compradora no obtenía la aprobación en el plazo referido, el contrato se resolvería de pleno derecho;

e) los contratantes, al señalar "aprobación previa", han querido referirse a que en el plazo de 180 días contados desde el 28 de julio de 1993 la demandada debía obtener la aprobación definitiva del proyecto del loteo general y del proyecto de urbanización del lote $\mathrm{D}$, lo que no sucedió, por lo que está en mora en el cumplimiento de dicha obligación;

f) la demandante no está en mora en el cumplimiento de su obligación de alzar parcialmente la hipoteca estipulada en su favor, desde que aquélla nacía sólo cuando se obtuviera la aprobación del proyecto de loteo y urbanización;

g) sin perjuicio que se ha ejercido la acción restitutoria por haber operado la resolución ipso facto del contrato, no puede entenderse que la Cooperativa demandante haya renunciado a la acción resolutoria; $y$

h) el hecho que la demandada no haya podido obtener agua potable para la parte del sitio ubicado en cotas superiores a la 58 no constituye fuerza mayor.

Séptimo: Que el primer error de derecho, como se ha visto, se sustenta en que la resolución de un contrato de compraventa por no pago de precio, que es lo alegado por la demandante, nunca opera de pleno derecho y, por el contrario, siempre requerirá de resolución judicial. Sin embargo, las partes acordaron que la obligación de la compradora, de pagar $\$ 359.135 .656$ a título de precio, se cumpliría a través de una dación en pago, esto es, con un objeto distinto al debido (con la construcción de 44 viviendas) y a juicio de este tribunal, la dación en pago tiene una individualidad propia, como un cumplimiento de la obligación por equivalencia libremente convenido por acreedor y deudor, de suerte que no debe confundirse esta institución con la compraventa ni con una modalidad del pago. Lo anterior lleva a concluir que si no se cumple con la convención contenida en la dación en pago -en el caso sub lite, si la compradora no obtiene el permiso municipal de construcción en el lapso convenido- y se ha estipulado un pacto 
comisorio calificado previendo este incumplimiento, producida la mora de la compradora, que es un presupuesto fáctico inamovible para esta Corte, la resolución del convenio opera ipso iure, desde que no nos encontramos frente al incumplimiento del pago del precio en un contrato de compraventa sino en el incumplimiento de la obligación contenida en la dación en pago pactada por las partes. No han cometido, entonces, los jueces del mérito, el error de derecho hecho valer por la sociedad demandada.

Octavo: Que en los otros cuatro capítulos de casación denunciados por la recurrente, ésta intenta desvirtuar los hechos fijados por los jueces del fondo y a los que se ha hecho referencia en el considerando sexto, pretendiendo que esta Corte revise tales presupuestos fácticos, lo que claramente no es posible en un recurso como el interpuesto, a menos que se hubiera dado por infringida alguna norma reguladora de la prueba en la fijación de tales hechos, lo que no ha sucedido, razón suficiente para desestimar estas alegaciones.

Noveno: Que en consecuencia, el recurso de casación en el fondo será, también, desechado.

Y visto, además, lo dispuesto en los artículos 767 y 768 del Código de Procedimiento Civil, se rechazan los recursos de casación en la forma y en el fondo deducidos a fs. 325 por el abogado Luis Valentín Ferrada Valenzuela en representación de Inversiones y Rentas San Pablo S. A., en contra de la sentencia de cuatro de octubre de mil novecientos noventa y nueve, escrita de fs. 322 a 323 vuelta.

Redacción a cargo del Abogado Integrante señor José Fernández Richard.

Regístrese y devuélvase con su agregado.

Pronunciado por los Ministros señores Humberto Espejo Z., Milton Juica A., el Fiscal Subrogante señor Carlos Meneses P. y los Abogados Integrantes señores José Fernández R. y René Abeliuk M.

\section{COOPERATIVA DE VIVIENDAS Y SERVICIOS HABITACIONALES RAFAEL SOTOMAYOR LIMITADA.}

RECURSO DE CASACIÓN.

Rol No 4.148 - 99 (Santiago). 